\title{
Experimental infection of turbot Scophthalmus maximus and halibut Hippoglossus hippoglossus yolk sac larvae with Aeromonas salmonicida subsp. salmonicida
}

\author{
Øivind Bergh ${ }^{1, *}$, Brit Hjeltnes ${ }^{2}$, Anne Berit Skiftesvik ${ }^{1}$ \\ ${ }^{1}$ Institute of Marine Research, Austevoll Aquaculture Research Station, N-5392 Storebø, Norway \\ ${ }^{2}$ Institute of Marine Research, Department of Aquaculture, PO Box 1870 Nordnes, N-5024 Bergen, Norway
}

\begin{abstract}
The susceptibility of early life stages of turbot Scophthalmus maximus and halibut Hippoglossus hippoglossus to Aeromonas salmonicida subsp. salmonicida was studied in challenge experiments. Eggs of both fish species (and the larvae hatching from the eggs) were exposed to the bacterium. Larvae of both species experienced mortality during the yolk sac stage, apparently as a result of the challenge. Examination of histological sections revealed degenerative changes in the skeletal muscle of both species of larvae. The bacterium could not be recovered from the larvae by culture, but it was shown to be present in the intestinal lumen of some of the turbot larvae examined using an immunohistochemical technique known to be specific for the bacterium. The results indicate that marine fish larvae exposed to $A$. salmonicida subsp. salmonicida may become infected and that the bacterium may persist in the larvae. Turbot larvae seemed to be more susceptible than halibut larvae.
\end{abstract}

KEY WORDS: Aeromonas salmonicida subsp. salmonicida - Fish larvae - Turbot - Halibut

\section{INTRODUCTION}

During outbreaks of typical furunculosis in Atlantic salmon Salmo salar, Aeromonas salmonicida subsp. salmonicida may be released in large numbers by infected fish (Enger et al. 1992). The bacterium can be detected in surrounding seawater and in the sediment beneath the net pens containing fish (Enger \& Thorsen 1992). Although A. salmonicida subsp. salmonicida occasionally causes disease in marine species such as cod Gadus morhua and halibut Hippoglossus hippoglossus and members of the wrasse family (Labridae), adult individuals of these species appear to be more resistant to this disease than salmonids (Hjeltnes et al. 1995). However, isolation of the bacterium from turbot Scophthalmus maximus experiencing significant mortality has been reported (Nougayrede et al. 1990. Toranzo \& Barja 1992, Pedersen \& Larsen 1996).

\footnotetext{
•E-mail: oivind bergh@imr.no
}

Marine fish larvae are susceptible to infection by opportunistic pathogenic bacteria (Bergh et al. 1992, Skiftesvik \& Bergh 1993). No information is available concerning the susceptibility of these larvae residing in the vicinity of net pens containing infected salmon releasing Aeromonas salmonicida subsp. salmonicida to the environment. The bacterium has been isolated from marine zooplankton (Nese \& Enger 1993), indicating that it can become associated with planktonic organisms, perhaps including yolk sac larvae of fish. The purpose of this study was to investigate the extent to which A. salmonicida subsp. salmonicida is able to become associated with, or even to infect and cause mortality of yolk sac larvae of 2 commercially important marine fish species, turbot and halibut.

\section{MATERIALS AND METHODS}

Source, cultivation, and preparation of the bacterium. The strain of Aeromonas salmonicida subsp. salmo- 
nicida used in this study was isolated from an outbreak of typical furunculosis in a stock of Atlantic salmon at the Institute of Marine Research, Matre Aquaculture Research Station, Matredal, Norway, in 1990. The strain is included in the culture collection of the Institute of Marine Research as strain number As 55 Matre. All incubation of the bacterium for the experiment with turbot was performed at $16^{\circ} \mathrm{C}$ in the climatecontrolled room in which the experiment with turbot larvae was performed. For the experiment with halibut all cultivation of bacteria was performed at $10^{\circ} \mathrm{C}$.

The different suspensions of the bacterium that were used in the experiments were obtained from exponentially growing cultures of As 55 Matre in Difco Marine Broth (Difco, Detroit, USA). The concentration of bacteria in the cultures was measured by plating on Tryptone Soya Broth (Oxoid, Basingstoke, England), 1.5\% agar (Difco), and 25\% seawater. After 1 wk of incubation, the concentration of bacteria was measured in terms of colony-forming units (CFU) per ml. Suspensions of washed bacteria and a suspension of heatkilled cells (turbot experiment only) were made immediately before infection of the fish eggs. The suspensions of washed bacterial cells were obtained by centrifugation of a volume of the culture and resuspension of the cells in an identical volume of $25 \%$ autoclaved seawater (SSW). The suspension of heat-killed cells was obtained by incubating a volume of the suspension of washed cells at $60^{\circ} \mathrm{C}$ for $30 \mathrm{~min}$.

Infection of turbot. One female turbot from the broodstock at the Austevoll Aquaculture Research Station was stripped and the resulting eggs were fertilized with sperm from a single male. The entire experiment was carried out in a climate-controlled room at $16^{\circ} \mathrm{C}$. The fertilized eggs were incubated in the dark for $2 \mathrm{~d}$ in stagnant seawater which had been stored and aerated at ambient temperature for at least $1 \mathrm{wk}$ prior to the experiment. The eggs were transferred to 24-well polystyrene multidishes (Nunc, Roskilde, Denmark) as described by Skiftesvik \& Bergh (1993). One egg was transferred to each well. Thereafter, the entire experiment was carried out in white light with an intensity of 117.4 lux. Approximately $24 \mathrm{~h}$ after transfer of the eggs to the multiwell dishes, the wells were inoculated with selected concentrations of the suspensions of the bacterium.

Three different amounts of the suspension of washed bacterial cells were added directly to the wells of 3 groups of eggs, $200 \mu \mathrm{l}$ (group As-A), $20 \mu \mathrm{l}$ (group As-B), and $2 \mu \mathrm{l}$ (group As-C), equivalent to final concentrations in the wells of $1.0 \times 10^{7}, 1.0 \times 10^{6}$, and $1.0 \times$ $10^{5} \mathrm{CFU} \mathrm{\textrm {ml } ^ { - 1 }}$, respectively. Three groups of eggs were exposed to equivalent amounts of a suspension of heatkilled cells. These groups were designated DC-A, $\mathrm{DC}-\mathrm{B}$, and DC-C (equivalent to As-A, As-B, and As-C, respectively). The last group of eggs served as a control group and nothing was added to these wells.

From each group, 3 multiwell dishes 72 individual eggs) were randomly selected. These eggs/larvae were inspected for mortality daily until termination of the experiment at Day 5 after hatching. The 96 individual eggs/larvae in the remaining 4 multiwell dishes were sequentially sampled for fixation for histological examinations, or attempts to re-isolate the pathogen.

Infection of halibut. One female of the halibut broodstock of the Austevoll Aquaculture Research Station was stripped and the resulting eggs were fertilized with sperm from 1 male. The eggs were reared in 250-L upwelling incubators as described by Pittman et al. (1990) at approximately $6^{\circ} \mathrm{C}$ for $7 \mathrm{~d}$.

From this stage onwards, the entire experiment was carried out in climate-controlled rooms at $6^{\circ} \mathrm{C}$. The eggs were transferred to polystyrene multidishes (Nunc, Roskilde, Denmark) according to Bergh et al. (1992). Each of these multiwell dishes had 6 separate identical wells, $35 \mathrm{~mm}$ in diameter and $18 \mathrm{~mm}$ deep. Each well contained $11 \mathrm{ml} \mathrm{SSW}$. One egg was transferred to each well. Two groups were included in this experiment. Group As was exposed to $100 \mu \mathrm{l}$ of the suspension of washed cells, equivalent to a concentration of bacteria in the wells of $10^{6} \mathrm{CFU} \mathrm{ml} l^{-1}$, approximately $24 \mathrm{~h}$ after transfer to the wells. In addition, there was a control group in which nothing was added to the wells.

One day after hatching, $10 \mathrm{ml}$ of water was removed from each well and $10 \mathrm{ml} \mathrm{SSW}$ was immediately added in order to remove the remains of the egg and eggshell from the wells. The eggs/larvae were incubated in darkness. Handling of the multiwell dishes, including inspection for mortality, was carried out in red light with an intensity of 2.5 lux. From each group, 10 multiwell dishes (60 individual larvae) were randomly selected and checked for mortality every second day until termination of the experiment at Day 29 after hatching. The remaining 180 individual larvae were used for sequential samplings for histological examination and attempts to re-isolate the pathogen.

Histological examinations. Apparently live samples of 6 to 8 larvae per group were fixed in $3.7 \%(\mathrm{vol} / \mathrm{vol})$ phosphate buffered formaldehyde at Days 1, 2, and 3 after hatching (turbot experiment) and at Days 1, 3, 7, 13, and 15 after hatching (halibut experiment). The larvae were embedded in paraffin, sectioned at $3 \mu \mathrm{m}$, stained with Giemsa, and examined using a light microscope.

For immunohistochemical examinations of the sections, a standard avidin-biotin-peroxidase complex (ABC) method was used (Hsu et al. 1981), modified as described by Evensen \& Rimstad (1990). Aeromonas salmonicida was identified by using a monoclonal antibody (D-5, National Veterinary Institute, Oslo, Nor- 
way), reactive with $A$. salmonicida lipopolysaccharide, diluted 1:100. Tris with 2.5\% Bovine Serum Albumin (BSA) was used as diluent. In the next 2 sequences, rabbit-anti-mouse immunoglobulins conjugated to biotin (Dakopatts) were used. The sections were then incubated with New Fuchsin substrate system, washed in tap water, and counterstained with Harris haematoxylin. Sections were mounted in an aqueous mounting medium. Staining controls were performed on tissue specimens from apparently healthy larvae.

Re-isolation of bacteria from larvae. In an attempt to re-isolate Aeromonas salmonicida subsp. salmonicida from the larvae, groups of 5 to 8 larvae were washed 3 times in SSW and homogenized. A dilution series was made from the homogenate and plated out on Tryptone Soya Broth and checked for growth of colonies resembling those of $A$. salmonicida subsp. salmonicida in pigment production and colony morphology.

Statistical analysis. For both experiments, differences between the experimental groups were tested for statistical significance by $\chi^{2}$ analysis, followed by comparison of groups with the Tukey-type multiple comparison of proportions (Zar 1984).

\section{RESULTS AND DISCUSSION}

In the turbot experiment, a dose-response in cumulative mortality was found for the groups exposed to washed bacteria (Fig. 1). No significant mortality took place at the egg stage, but after hatching, the mortality increased in group AsA from Day 1 onwards. The difference between group As-A and the control group was significant from Day 1 onwards $(p<0.025)$. None of the remaining groups showed mortalities significantly different from the control group. Pathological changes were found in 3 out of 11 turbot larvae from group As-A sampled on Days 2 and 3. The changes were evident as sloughing of the intestinal epithelium and degenerative changes in the skeletal muscle (Fig. 2). No such changes were found in the 4 turbot larvae sampled from this group on Day 1. No changes were found in a total of 5 larvae from the control group or in 7 larvae from group DC-A that were checked. In 1 of the turbot larvae with pathological changes, and in 4 of the other larvae from group As-A, cell-like structures associated with bacteria were seen in the intestine and the oesophagus
(Fig. 3a, b). These cell-like structures were associated with positive immunohistochemical staining in 3 of the turbot larvae (Fig. $3 c$ ). The attempts to re-isolate the pathogen from the larvae failed, as no colonies resembling those of Aeromonas salmonicida subsp. salmonicida and producing pigment were found.

In the halibut experiment, no mortality took place during the egg stage, and the mortality of the larvae was low the first $3 \mathrm{~d}$ after hatching (Fig. 4). Thereafter, the mortality increased in the challenged group, but it was lower in the control group. The difference between the control group and the challenged group was significant from Day 5 onwards $(p<0.05)$. Three out of 9 of the halibut larvae from the challenged group sampled at Day 13 were characterized by degenerative changes (pycnotic nuclei) in the skeletal muscle. However, similar changes were also found in 3 out of 6 halibut larvae from the control group at Days 13 and 15. No pathological changes were found among halibut larvae sampled earlier. As with the the case of turbot, Aeromonas salmonicida subsp. salmonicida was not re-isolated from the larvae, but unlike the result from the turbot experiment, no halibut larvae gave positive immunohistochemical reactions for $A$. salmonicida subsp. salmonicida.

The results demonstrate a significantly increased mortality of both species of fish larvae following exposure to Aeromonas salmonicida subsp. salmonicida, compared to the uninfected control groups. The absence of increased mortality in the groups of turbot larvae that were exposed to heat-killed cells rules out

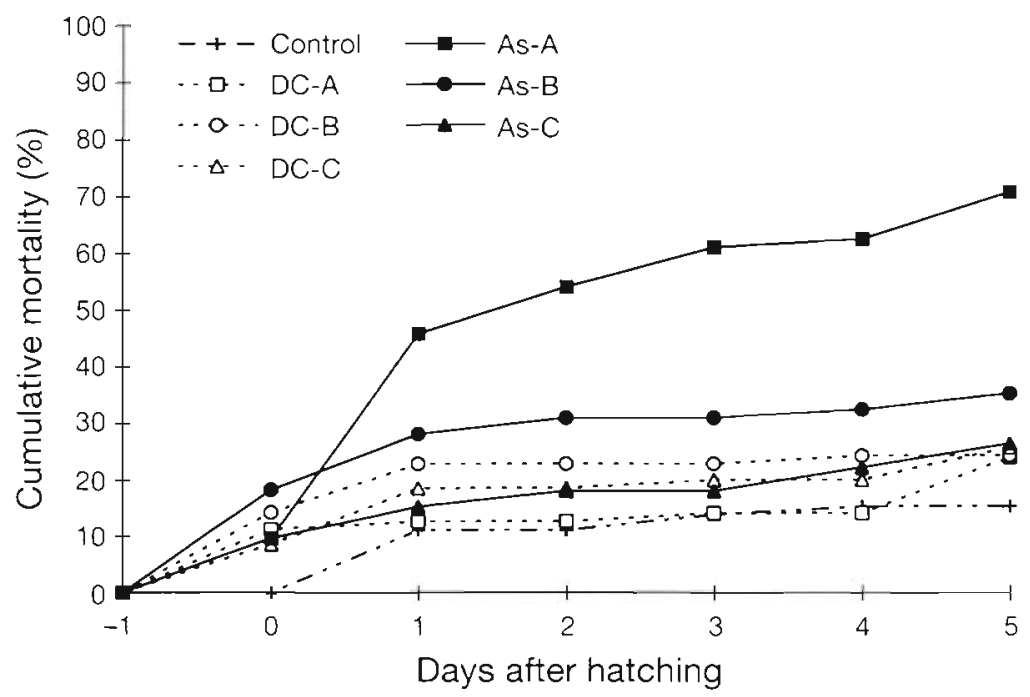

Fig. 1. Cumulative mortality (\%) in the experiment with turbot larvae challenged with Aeromonas salmonicida subsp. salmonicida. The groups are As-A, As-B, and As-C (exposed to various levels of viable, washed cells); DC-A, DC-B, and DC-C (exposed to equivalent amounts of heat-killed cells); and control (nothing added to the wells). Each group consisted of 72 individual eggs/larvae 


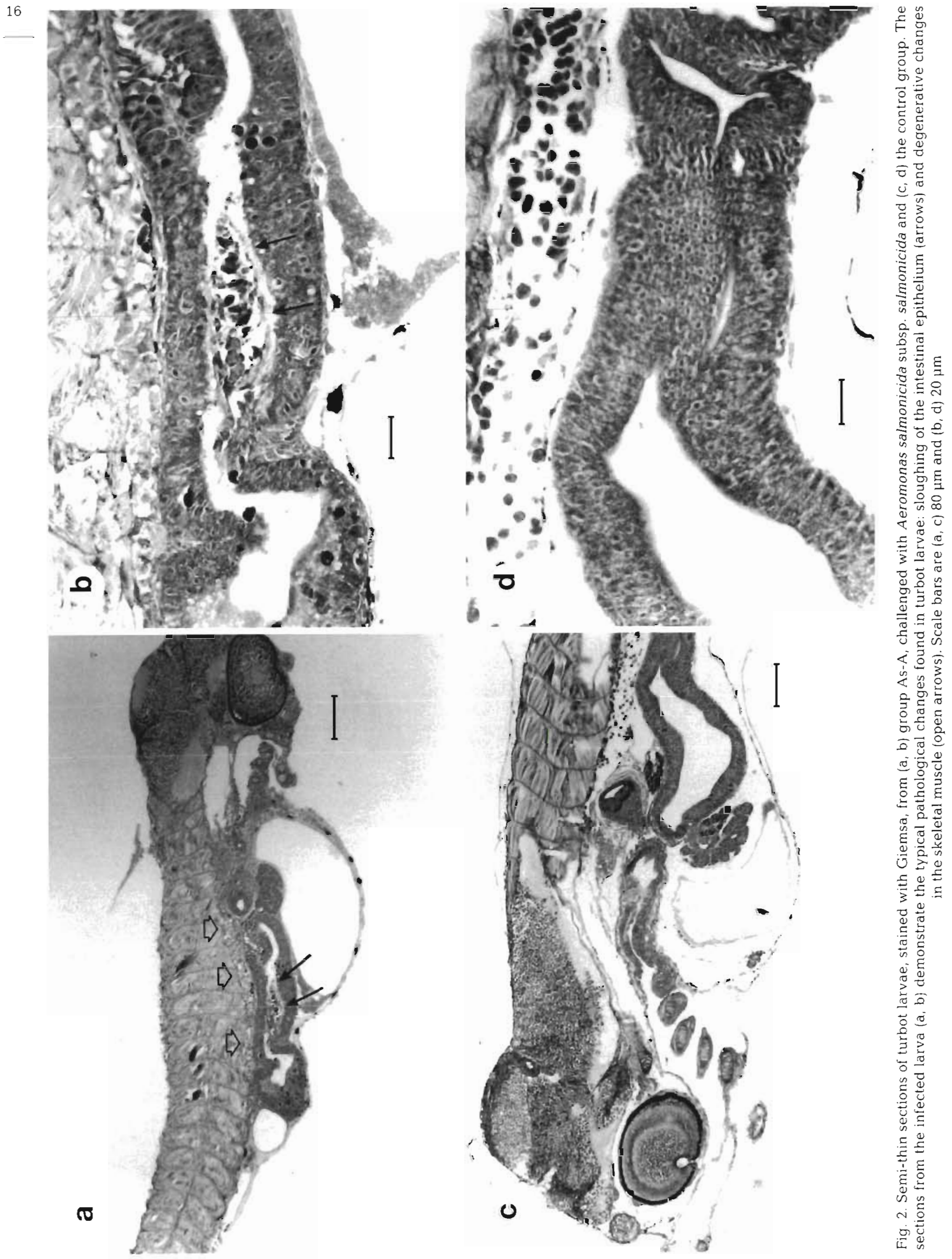




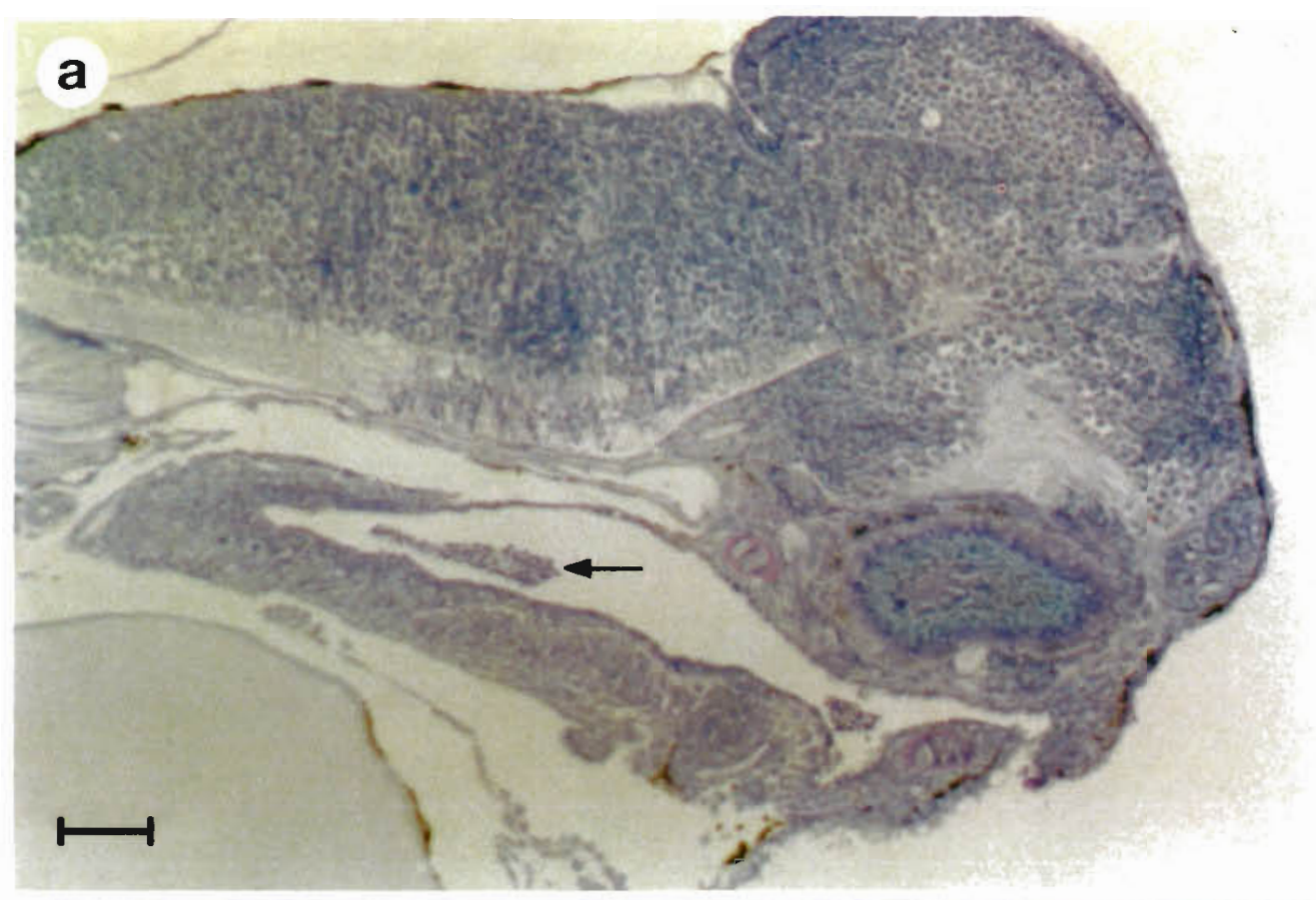

Fig. 3. Semi-thin sections from a turbot larva of (a, b) group As-A, challenged with Aeromonas salmonicida subsp. salmonicida stained with Giemsa or (c) with the immunohistochemical stain to visualize this bacterium. The arrow in (a) points out the area of the oesophagus enlarged in (b) and (c). Cell-like structures can be seen $(b, c)$, associated with positively red-stained [arrow in (c)] bacteria-like structures [arrow in (b)]. Scale bars are (a) $40 \mu \mathrm{m}$ or (b, c) $10 \mu \mathrm{m}$

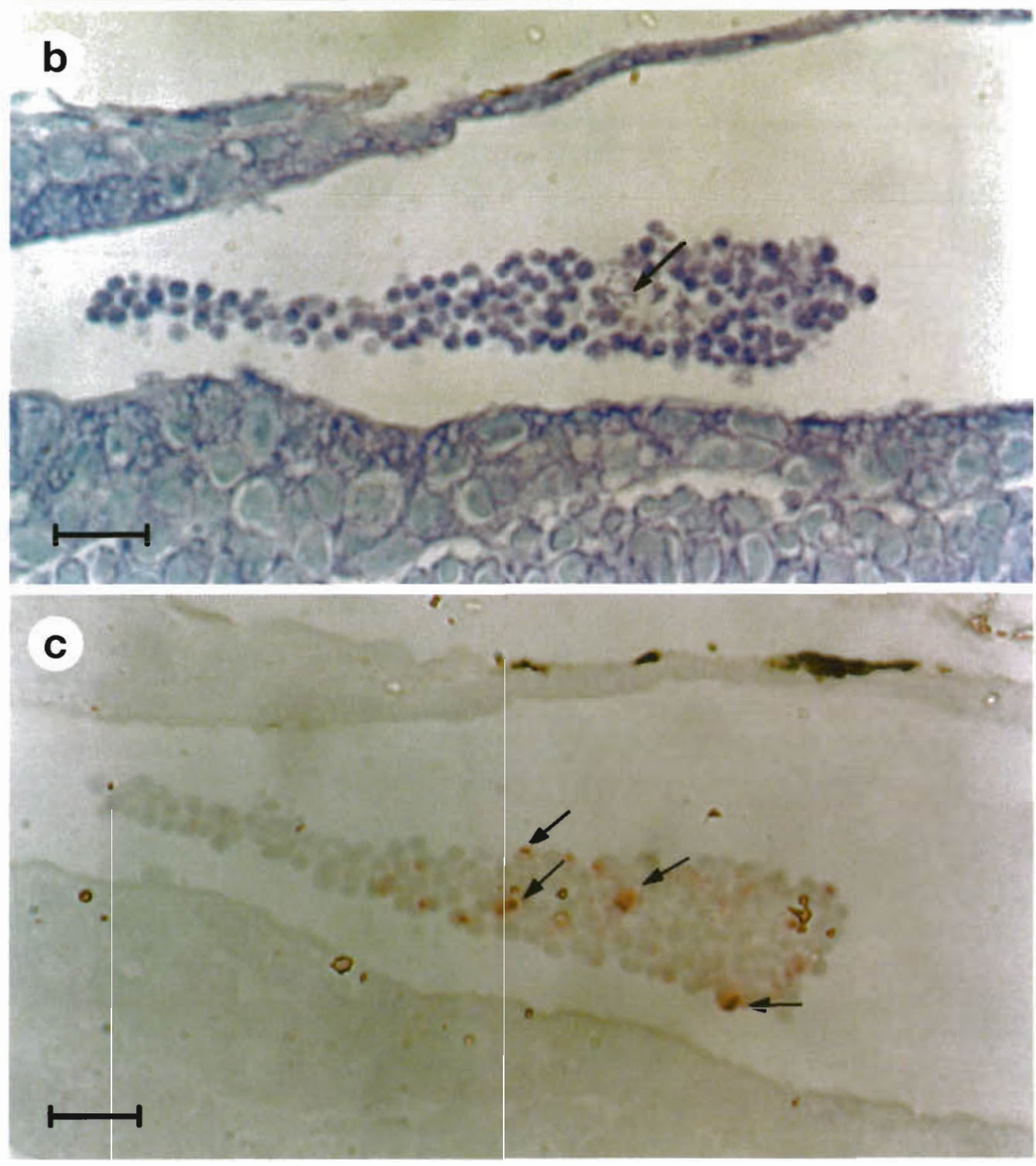




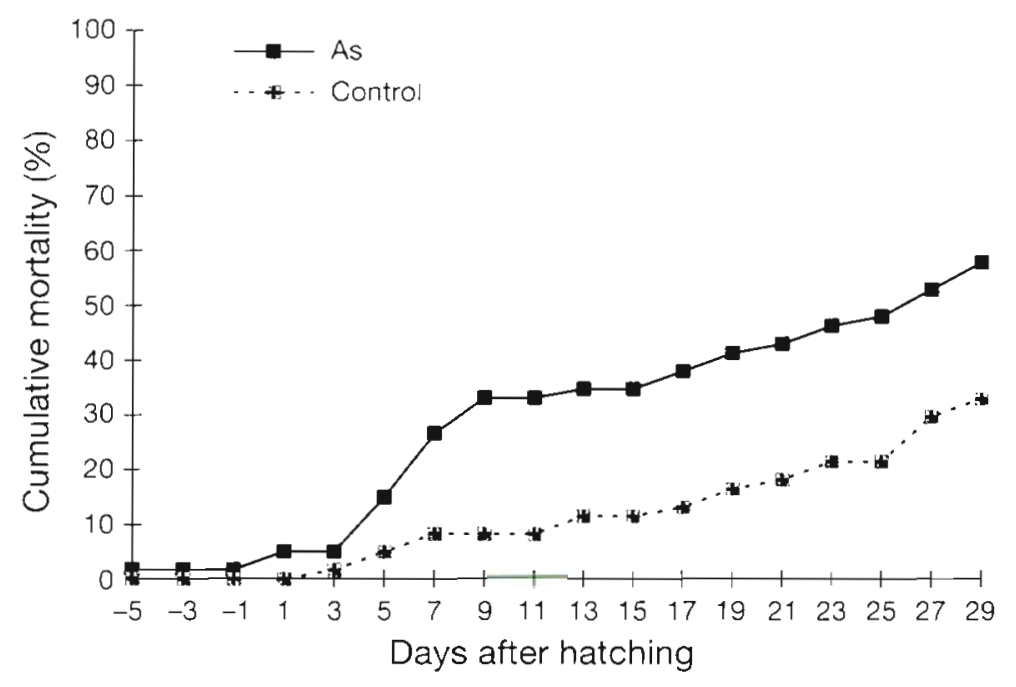

Fig. 4. Cumulative mortality $(\%)$ in the experiment with halibut larvae challenged with Aeromonas salmonicida subsp salmonicida. The groups are As (exposed to viable, washed cells), and control (nothing added to the wells). Each group consisted of 60 individual eggs/larvae
1992, Pedersen \& Larsen 1996). Thus, it seems that differences in host susceptibility to a given pathogen could be present as early as the yolk sac stage.

The differences in rearing temperature between the turbot and halibut experiments undoubtedly also contributed to the results. In our experiments, both species of larvae were reared close to the optimal temperature of the species. Halibut larvae, which are commonly reared at 5 to $8^{\circ} \mathrm{C}$, would not have been able to survive at the temperatures used in the experiment with turbot (Pittman et al. 1990). This necessitated a temperature lower than the temperatures at which epizootics with Aeromonas salmonicida subsp. salmonicida in salmon occur, typically 12 to $18^{\circ} \mathrm{C}$ (Hjeltnes et al. 1995). Thus, turbot larvae have a greater overlap in temperature range with $A$. salmonicida subsp. salmonicida than halibut larvae.

Turbot also have greater overlap in spatial distribution with the bacterium than halibut, as they occur naturally in the upper $10 \mathrm{~m}$ of the water column (Nellen \& Hempel 1970) as a result of their specific density. They may thus experience contact with the lipid microlayer found at the air-water interface in marine systems (Norkrans 1980, Dahlback et al. 1981, 1982) where Aeromomas salmonicida subsp. salmonicida can occur in high numbers. It seems evident from buoyancy measurements in laboratory experiments (Skiftesvik \& Bergh 1993) that halibut larvae have higher specific density than turbot larvae. Due to its high hydrophobicity, $A$. salmonicida subsp. salmonicida aggregates in the surface layer, and an average of $4.3 \times 10^{3}$ A. salmonicida subsp. salmonicida $\times \mathrm{ml}^{-1}$ was reported by Enger \& Thorsen (1992) for a sampling station within a furunculosis-affected salmon farm. This was 1 to 2 orders of magnitude higher than in the water column immediately below the surface layer. In samples from the sediment beneath, an average of $2.2 \times 10^{6}$ A. salmonicida subsp. salmonicida $\times \mathrm{ml}^{-1}$ was found. Although such microenvironments might possess relatively high concentrations of $A$. salmonicida subsp. salmonicida, it should be noted that all concentrations measured by immunofluorescence counts in the field study by Enger \& Thorsen (1992) were lower than our measurements by viable counts in group As-A at the time of infection.

It is possible that the ability to occur in association with fish larvae constitues a survival strategy for Aeromonas salmonicida subsp. salmonicida. The bacterium is highly hydrophobic and has been isolated from zooplankton and salmon lice (Nese \& Enger mortalities have been reported in farme specimens (Nougayrede et al. 1990, Toranzo \& Barja 
1993). Effendi \& Austin (1994) noted that the shortest survival (measured as CFU) of starved cells of $A$. salmonicida subsp. salmonicida was in seawater controls, whereas cells attached to wood, seaweeds or invertebrate animals survived for comparatively longer periods. A. salmonicida subsp. salmonicida may also become associated with wild fish in the vicinity of fish farms affected by furunculosis. The bacterium has been isolated from wild cod Gadus morhua and coalfish (Pollachius virens) captured within a range of $200 \mathrm{~m}$ from fish farms affected by furunculosis (Willumsen 1990). Samuelsen et al. (1992) demonstrated the presence of the bacterium in the gut of wild salmon and coalfish in the vicinity of a fish farm. A special case is the outbreak of disease in goldsinny Ctenolabrus rupestris and rock cook $C$. exoletus used as cleaner fish for salmon infested with lice and furunculosis (Treasurer \& Laidler 1994). These studies demonstrate the capability of the bacterium to persist, at least for some time, in the gastrointestinal tract of certain fish species. Adult and larval stages of several fish species may thus be vectors for the bacterium.

Our attempts to re-isolate the bacterium failed, and it is generally considered difficult to isolate Aeromonas salmonicida subsp. salmonicida from planktonic organisms (Nese \& Enger 1993) or from samples containing other fast-growing bacteria. The immunohistochemical signal was relatively weak, indicating a low number of $A$. salmonicida subsp. salmonicida present in the infected larvae. In addition, as evident by culture, a variety of different bacteria were isolated from the larvae, probably originating from the gastrointestinal tract and the skin. It is possible that the use of more sophisticated diagnostic methods, like isolation of the bacterium by use of immunomagnetic beads would have detected the pathogen.

In conclusion, the results indicate that high concentrations of Aeromonas salmonicida subsp. salmonicida during outbreaks of furunculosis in salmon farms might affect marine fish larvae in the vicinity of the farms. The turbot larvae seemed susceptible to infection by $A$. salmonicida subsp. salmonicida. Although pathological changes and increased mortality were found for both species, evidence implicating A. salmonicida subsp. salmonicida as the cause was stronger for turbot than for halibut.

Acknowledgements. Funds for this study were provided by the Norwegian Research Council, Grant Nos. 1203-701.433 and 1401-701.424. Technical assistance by Laila Baardset and Ingrid Uglenes is highly appreciated. We also thank Dr Øystein Evensen of the National Veterinary Institute, who provided the monoclonal antibody, and Dr Johan Glette for his comments on the manuscript.

\section{LITERATURE CITED}

Bergh $\varnothing$, Hansen GH, Taxt RE (1992) Experimental infection of eggs and yolk sac larvae of halibut, Hippoglossus hippoglossus L. J Fish Dis 15:379-391

Bergh $\varnothing$, Jelmert A (1996) lodophor disinfection of eggs of Atlantic halibut. J Aquat Anim Health 8:135-145

Dahlback B, Gunnarson LA, Hermannsson M, Kjelleberg S (1982) Microbial investigations of surface microlayers, water column, ice and sediment in the Arctic Ocean. Mar Ecol Prog Ser 9:101-109

Dahlback B, Hermannsson M, Kjelleberg S, Norkrans B (1981) The hydrophobicity of bacteria - an important factor in the initial addition at the air-water interface. Arch Microbiol 128:267-270

Effendi I, Austin B (1994) Survival of the fish pathogen Aeromonas salmonicida in the marine environment. J Fish Dis 17:375-385

Enger Ø, Gunnlaugsdottir B, Thorsen BK, Hjeltnes B (1992) Infectious load of Aeromoas salmonicida subsp. salmonicida during the initial phase of a cohabitant infection experiment with Atlantic salmon (Salmo salar). J Fish Dis 15:425-430

Enger $\oslash$, Thorsen BK (1992) Possible ecological implications of the high cell surface hydrophobicity of the fish pathogen Aeromonas salmonicida. Can J Microbiol 38(10): 1048-1052

Evensen $\varnothing$, Rimstad $E$ (1990) Immunohistochemical identification of infectious pancreatic necrosis virus in paraffinembedded tissues of Atlantic salmon (Salmo salar). J Vet Diagn lnvest 2:288-293

Hjeltnes B, Bergh $\varnothing$. Wergeland H, Holm JC (1995) Susceptibility of Atlantic cod Gadus morhua, halibut Hippoglossus hippoglossus and wrasse (Labridae) to Aeromonas salmonicida subsp. salmonicida and the possibility of transmission of furunculosis from farmed salmon Salmo salar to marine fish. Dis Aquat Org 23:25-31

Hsu SM, Raine L, Fanger H (1981) Use of an avidin-biotinperoxidase complex. ( $A B C$ ) in immunoperoxidase techniques. A comparison between $A B C$ and unlabelled antibody (PAP) procedures. J Histochem Cytochem 29: $577-580$

Nellen W, Hempel G (1970) Beobachtungen am Icthyoneuston der Nordsee. Ber Dt Wiss Komm Meeresforsch 21:311-348

Nese L, Enger $\varnothing$ (1993) Isolation of Aeromonas salmonicida from salmon lice Lepeophtheirus salmonis and marine plankton. Dis Aquat Org 16:79-81

Norkrans B (1980) Surface microlayers in aquatic environments. Adv Microb Ecol 4:51-85

Nougayrede P, Sochon E, Vuilaume A (1990) Isolation of Aeromonas subspecies salmonicida in farmed turbot (Psetta maxima) in France. Bull Eur Ass Fish Pathol 10: $139-140$

Pedersen K, Larsen JL (1996) First report on outbreak of furunculosis in turbot, Scophthalmus maximus caused by Aeromonas salmonicida subsp. salmonicida in Denmark. Bull Eur Ass Fish Pathol 16(4):129-133

Pittman K, Bergh $\varnothing$. Opstad I, Skiftesvik AB, Skjolddal L, Strand H (1990) Development of eggs and yolk sac larvae of halibut (Hippoglossus hippoglossus L.). J Appl Ichthyol $6: 142-160$

Samuelsen OB, Lunestad BT, Husevåg B, Holleland T, Ervik A. (1992) Residues of oxolinic acid in wild fauna following medication in fish farms. Dis Aquat Org 12:111-119

Skiftesvik AB, Bergh $\varnothing$ (1993) Changes in behaviour of Atlantic halibut (Hippoglossus hippoglossus) and turbot 
(Scophthalmus maximus) yolk-sac larvae induced by bacterial infections. ('an J Fish Aquat Sci 50:2552-2557

Toranzo AE, Barja IL (1992) First report of furunculosis in turbot reared in flodting cages in northwest of Spain. Bull Eur Ass Fish Pathol 12:147-149

Treasurer JW, Lailder LA (1994) Aeromonas salmonicida infection in wrasse (Labridae) used as cleaner fish, on an

Responsible Subject Editor: T. P. T. Evelyn, Nanaimo, British Columbia, Canada
Atlantic salmon, Salmo salar L., farm. J Fish Dis 17 $155-161$

Willumsen B (1990) A. salmonicida subsp. salmonicida isolated from atlantic cod and coalfish. Bull Eur Ass Fish Pathol 10:62-64

Zar JH (1984) Biostatistical analysis, 2nd edn. Prentice-Hall Inc, Englewood Cliffs, NJ

Manuscript first received: March 14, 1995

Revised version accepted: September 26, 1996 